\title{
POTENCIAL DE MOVIMENTO DE MASSA NO MUNICÍPIO DE MACEIÓ-ALAGOAS
}

\section{POTENTIAL OF MASS MOVEMENT IN THE CITY OF MACEIÓ- ALAGOAS}

\author{
Bruno Timóteo Rodrigues \\ IGDEMA/UFAL \\ brunogta12@gmail.com \\ Sivana Quintella Cavalcanti Calheiros \\ IGDEMA/UFAL \\ qsilvana@uol.com.br \\ Nivaneide Alves de Melo \\ IGDEMA/UFAL \\ nivaneide.ufal@yahoo.com.br
}

\section{RESUMO}

O Brasil está entre os dez países mais atingidos por desastres naturais no mundo e os deslizamentos constituem-se em um dos principais riscos geológicos do País, podendose apontar situações ocorridas no Rio de Janeiro, Alagoas e Pernambuco. O objetivo do presente trabalho foi investigar a partir de uma base de dados georreferenciada, áreas potenciais para prováveis desastres ambientais, considerando as alterações e relações espaciais produzidas sobre uma estrutura ambiental e socioeconômica do município de Maceió. A análise foi realizada por geoprocessamento, cujo Sistema Geográfico de Informação utilizado foi o Sistema de Análise Geoambiental (S.A.G.A. - UFRJ), fazendo-se uso de uma base de dados, que se constitui de diversos mapas temáticos, os quais foram executadas planimetrias, análises prospectivas (assinaturas ambientais) e avaliações ambientais das situações ambientais identificadas: movimentos de massa. A avaliação potencial ambiental para movimento de massas é identificado como um dos definidores de ocorrência de desastres naturais. As avaliações conduziram à identificação de áreas potenciais para ocorrência de movimento de massas potenciais a desastres naturais. O Sistema Geográfico de Informação apresentou uma visão integradora, sendo um poderoso instrumento de análise ambiental visando o apoio a decisão.

Palavras-chave: Análise Ambiental, Meio Ambiente, Vulnerabilidade, Geoprocessamento, Sistema de Informação Geográfica

\footnotetext{
ABSTRACT

Brazil is more enters the 10 countries reached by natural disasters in the world and the landslides consist in one of the main geologic risks of the Country, being able themselves to point occured situations in Rio de Janeiro, Alagoas and Pernambuco. The objective of the present work was to investigate from a database georreferenciada, 
potential areas for probable ambient disasters, considering the produced alterations and space relations on an ambient and socioeconômica structure of the city of Maceió. The analysis was carried through by geoprocessamento, whose Geographic System of used Information was the System of Analysis Geoambiental (S.A.G.A. - UFRJ), becoming use of a database, that if constitutes of diverse thematic maps, which on this base had been prospectivas planimetrias, analyses (ambient signatures) and ambient evaluations of the identified ambient situations: mass movements. The ambient potential evaluation for movement of masses is identified as one of the defining ones of occurrence of natural disasters. The evaluations had lead to the identification of potential areas for occurrence of movement of masses of potential natural disasters. The Geographic Systems of Information presented a vision integrator, being a powerful instrument of ambient analysis aiming at the support the decision.

Keywords: Environmental Analysis, Ambient environment, Vulnerability, Geoprocessing, Geography Information Sistem

\section{INTRODUÇÃO}

Movimentos de Massas são processos dinâmicos, de ocorrência em vertentes, sendo a principal situação ambiental para ocorrência de desastres naturais (FERNANDES e AMARAL 1996; SILVA, 2011; BISPO et. al., 2011 e SOUZA, 2004). Nos últimos anos tem-se verificado no Brasil desastres naturais de grande magnitude, como as ocorridas no Rio de Janeiro (Petrópolis e Angra dos Reis), Alagoas (União dos Palmares, Rio Largo e Branquinha), Pernambuco (Barreiros), dentre outros.

Esses desastres são considerados fenômenos naturais que atingem áreas ou regiões habitadas pelo homem, causando-lhe danos ou como uma grave perturbação do funcionamento de uma comunidade e/ou sociedade envolvendo perdas humanas, materiais, econômicas ou ambientais de grande extensão, cujos impactos excedem a capacidade da comunidade ou da sociedade afetada de arcar com seus próprios recursos (TOMINAGA et. al., 2009).

Assim, prevenção e ações emergenciais que venham a evitar ou minimizar situações de desastres naturais pelos órgãos competentes, necessitam de tomadas de decisões sustentadas na realidade física e socioambiental da área de ocorrência.

A dinâmica do relevo relaciona-se tanto com o tipo e estrutura das rochas, como com as variáveis climáticas, atuação de fauna e flora (CHRISTOFOLETTI, 1974). Como parte dessa dinâmica ocorre os processos de vertente, entre os quais, os movimentos de massa, que envolvem o desprendimento e transporte de solo e/ou material rochoso para a base da vertente. A mobilização de material deve-se à sua 
condição de instabilidade, devido à atuação da gravidade, podendo ser acelerada pela ação de outros agentes, como a água.

O deslocamento de material ocorre em diferentes escalas e velocidades, variando de rastejamentos a movimentos muito rápidos (CHORLEY et. al., 1984). Os movimentos rápidos, denominados genericamente de deslizamentos e tombamentos têm grande importância, devido à sua interação com as atividades antrópicas e à variabilidade de causas e mecanismos (IPT, 1989). Os deslizamentos e tombamentos são deflagrados pelo aumento de solicitação de mobilização de material (erosão, energia cinética da chuva) e pela redução da resistência do material (ação desagregadora de raízes, rastejamentos, textura e estrutura favoráveis à instabilidade). Quando os movimentos de massa são tratados na perspectiva de relação entre eventos naturais e ação antrópica, o fenômeno é enquadrado como risco, ou seja, fenômenos de origem natural ou induzidos e que acarretam prejuízos aos componentes do meio biofísico e social.

O aumento de população tem levado à ocupação, tanto para a moradia (principalmente por parte de população de baixa renda) quanto para o lazer, de áreas de risco potencial. Essa situação tem levado ao aumento de frequência (repetitividade de fenômenos ao longo do tempo) e magnitude (extensão e impacto) dos movimentos de massa. Os problemas relativos à erosão e a processos de movimentos de massa encontram-se presentes numa situação socioeconômica considerada como de subdesenvolvimento ou em desenvolvimento, no qual os problemas tornam-se mais acentuados devido à escassa estrutura para evitar ou controlar tal fenômeno (GUERRA, 2011).

Desse modo são necessárias pesquisas voltadas a estudos ambientais, visando fornecer subsídios básicos a um planejamento territorial municipal voltado para diagnósticos e prognósticos baseados em inventários, monitoramentos e avaliações ambientais, com definições de áreas potenciais para ocorrência de desastres ambientais e impactos da ocupação humana sobre o território (GOES, 1994).

Esse tipo de estudo é escasso em Maceió, haja vista que a publicação mais recente sobre a temática no município é de 2004 (ANJOS, 2004), onde aborda a dicotomia sócio-ambiental na ocupação de encostas urbanas. 
Diante deste contexto objetivou-se com este trabalho investigar a partir de uma base de dados georreferenciada, áreas potenciais para prováveis desastres ambientais, considerando as alterações e relações espaciais produzidas sobre uma estrutura ambiental e socioeconômica do município de Maceió.

\section{MATERIAL E MÉTODOS}

\section{Caracterização da área de estudo}

A área da pesquisa representada pelo município de Maceió está localizado entre o oceano e lagunas. Maceió encontra-se no centro da faixa litorânea alagoana, inserida na Microrregião homonímia e Mesorregião do Leste, (Figura 1).

O município de Maceió ocupa uma área de $503,7 \mathrm{~km}^{2}$, com altimetria variando entre 0 e 20 m na planície litorânea, passando entre 20 e 180 m no topo e encostas dos tabuleiros e $300 \mathrm{~m}$ no topo da Serra da Saudinha.

Apresenta um período chuvoso (outono/inverno) e outro seco (primavera/verão), resultado da influência do sistema de circulação intertropical que desenvolve climas controlados por massas quentes equatorial (Centro dos Açores) e tropical (anticiclone do Atlântico Sul). Da ação desses sistemas e da localização da área em baixas latitudes, resultam as temperaturas elevadas e precipitações abundantes.

As precipitações variam de $300 \mathrm{~mm}$ em junho e julho a $50 \mathrm{~mm}$ em dezembro, elementos que definem seu clima quente e úmido sem grandes diferenciações térmicas (SOUZA e AQUINO, 1997; SOUZA et. al., 1998). As temperaturas médias mensais é de $24^{\circ} \mathrm{C}$. A máxima mensal atinge $26^{\circ} \mathrm{C}$ e a mínima $23^{\circ} \mathrm{C}$, com pequenas oscilações, ou seja, amplitude térmica de $3^{\circ} \mathrm{C}$. As temperaturas verificadas são amenizadas pela presença da maritimidade, proporcionando elevada umidade relativa do ar, variando entre 75 e $82 \%$ durante todo o ano, sendo os meses de maio e junho os mais úmidos e os de novembro e dezembro os mais secos (SOUZA e AQUINO, 1997).

Quanto ao substrato geológico este é constituído pela umidade estratigráfica vinculada ao Cenozóico. O município de Maceió, está vinculada ao Cenozóico que segundo DNPM (1986) corresponde aos sedimentos Quaternários, litologias Terciárias e esparsos afloramentos de litologias vinculadas ao Cretáceo inferior.

Geo UERJ - Ano 15, no. 24, v. 1, $1^{\circ}$ semestre de 2013 p. 207-227

ISSN: 1415-7543E-ISSN: 1981-9021

http://www.e-publicacoes.uerj.br/index.php/geouerj 

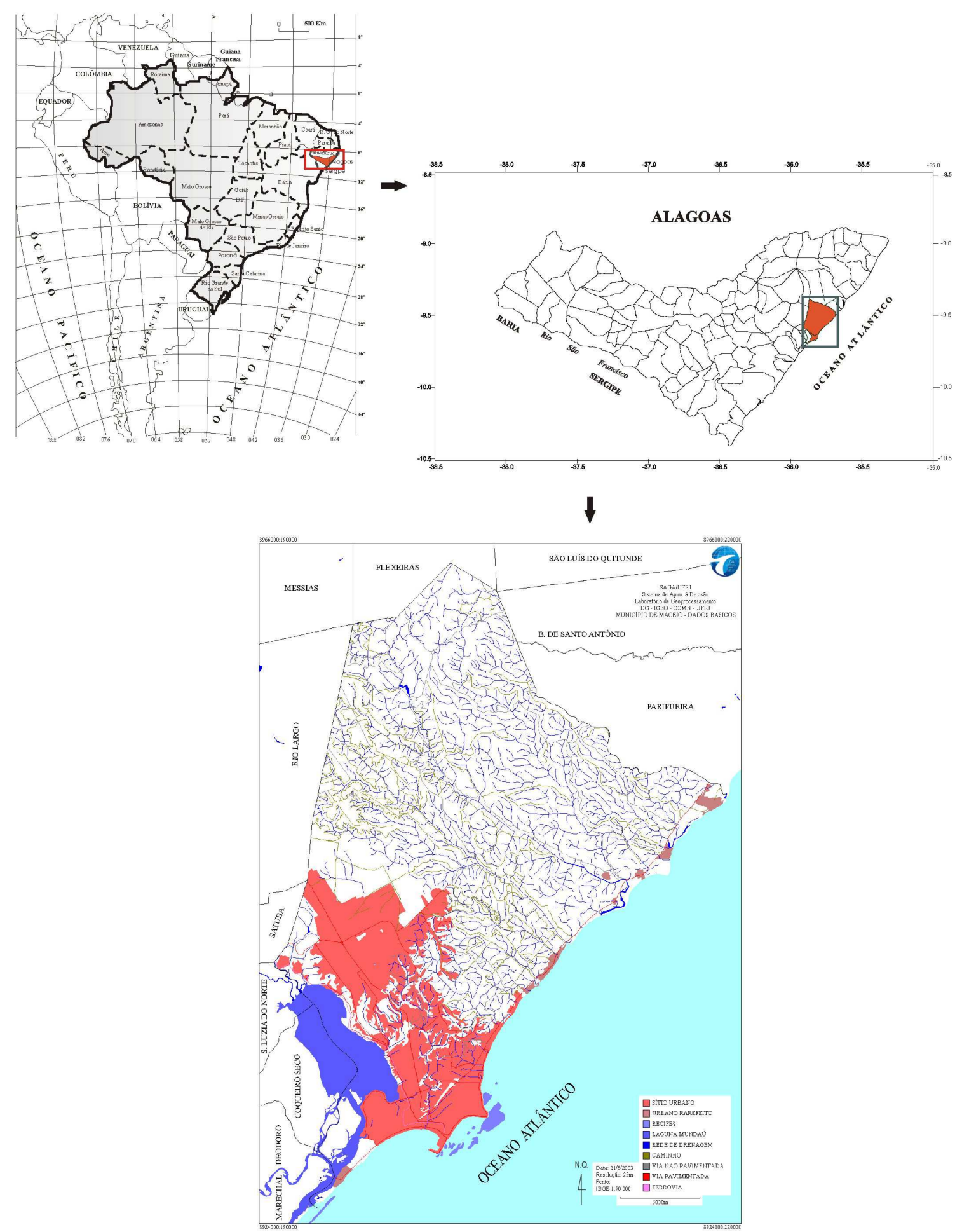

Figura 1 - Mapa de Localização de Maceió - AL.

Geo UERJ - Ano 15, no. 24, v. 1, $1^{\circ}$ semestre de 2013 p. 207-227

ISSN: 1415-7543E-ISSN: 1981-9021

http://www.e-publicacoes.uerj.br/index.php/geouerj 
Quando ao relevo destacam-se tabuleiros costeiros (RADAM BRASIL, 1983), formando um corpo alongado acompanhando o litoral com altitudes máximas de $150 \mathrm{~m}$ de relevo ligeiramente plano com declividade suave em direção a SE, interrompido para leste, formando falésias retilíneas cuja escarpas expõe os arenitos friáveis em cores variadas da Formação Barreiras e eventualmente, na parte inferior, os sedimentos cretácicos. Segundo Ponte (1969) os topos dessas escarpas não excedem $50 \mathrm{~m}$ de altitude. Também destaca-se a Planície Litorânea, com unidades estuarinas, praiais, dunares e cordões litorâneos. A leste, à frente das planícies litorâneas ao longo de toda costa, encontra-se refices de deposição de arenitos e de corais.

Nesses ambientes, os estágios vegetacionais se apresentam, segundo ASSIS (2000), como vegetação correspondente à Floresta Subperenifólia de Restinga, Formação de Praias e Dunas, Formação de Mangues ou Manguezais, Campos de Restinga e Campos de Várzea.

A área de estudo é possuidora de alterações (urbano, insdústria, turismo e agricultura) dando origem a pressões na organização espacial. O último evento de desastres naturais ocorridos nesse município tem nos movimentos de massas como fenômeno de maior recorrência identificado por trabalho de campo, documentos cartográficos do município.

\section{Obtenção e geração dos dados}

As avaliações das áreas de potenciais irão resultar da combinação de dados previamente inventariados, gerando neste caso o potencial ambiental para ocorrência de movimento de massa. Entende-se por potencial ambiental, o levantamento das condições ambientais existentes na área, onde são identificadas a extensão e possível expansão do processo ambiental, no caso movimentos de massa. Os procedimentos de análise foram desenvolvidos em três módulos: aquisição, identificação dos fenômenos e eventos para ocorrência de desastres naturais, além de análises por geoprocessamento.

Os dados foram obtidos a partir de trabalho de campo, análises estatísticas e interpretações de documentos cartográficos e de imagens de satélites.

Além de levantamento bibliográfico, cartográfico e consultas a bancos de dados existentes, tendo como produto final a identificação dos fenômenos e eventos 
ambientais relevantes ameaçadores e avaliação do potencial de risco para movimentos de massa.

Utilizou-se da base de dados geográfica digital, estruturadas em um Sistema Geográfico de Informação de Maceió, do Laboratório de Geoprocessamento Aplicado (LGA/IGDEMA/UFAL), contendo os parâmetros: Geomorfologia, Declividade, Litologia e Altitude, com resolução 25 m, referente ao ano de 2004.

Foi utilizado o software Vista S.A.G.A. da UFRJ, que é um sistema geográfico de informação (SGI) (CARVALHO FILHO e ABDO, 1999). Este software apresenta um módulo próprio para realização das avaliações ambientais que consiste no entrecruzamento ou combinação dos mapas (variáveis) utilizando-se média aritmética ponderada.

As avaliações por geoprocessamento constituíram em uma forma de prospecção ambiental (XAVIER-DA-SILVA e CARVALHO FILHO, 1993) e resultou na delimitação de áreas específicas para uma determinada utilização (risco e potencial).

Os procedimentos analíticos aplicados a estudos geoambientais variam segundo a escala de investigação adotada (CALHEIROS, 2000).

Nesta análise os elementos de avaliação foram realizados a partir da atribuição de pesos percentuais ( 0 a 100\%) para cada parâmetro selecionado, seguido de notas ( 0 a 10). Estas foram atribuídas segundo grau de possibilidade de ocorrência e organização da distribuição espacial. As notas atribuídas às classes dos mapas variaram de 0-10 e as classes com uma participação nula (nota=0) ou quase nula (nota=1), com pequena participação receberam (notas de 2 a 4), com participação média (notas entre 5 e 6), com grande participação (notas entre 7 e 8), nas classes onde as ocorrências eram muito possíveis (notas=9) e extremamente possíveis (nota=10). Resultando no mapa de áreas potenciais para movimentos de massa no município de Maceió.

Para efetivar as análises foram selecionados os parâmetros, exemplificado apenas por duas variáveis selecionadas (Figuras 2 e 3). Para essa análise foram definidas como variáveis ambientais (planos de informação) participantes da avaliação: geomorfologia, altitude, litologia, declividade e macromodelados, selecionadas na base de dados.

Geo UERJ - Ano 15, no. 24, v. 1, $1^{\circ}$ semestre de 2013 p. 207-227

ISSN: 1415-7543E-ISSN: 1981-9021

http://www.e-publicacoes.uerj.br/index.php/geouerj 
DOI: $10.12957 / g e o u e r j .2013 .5351$

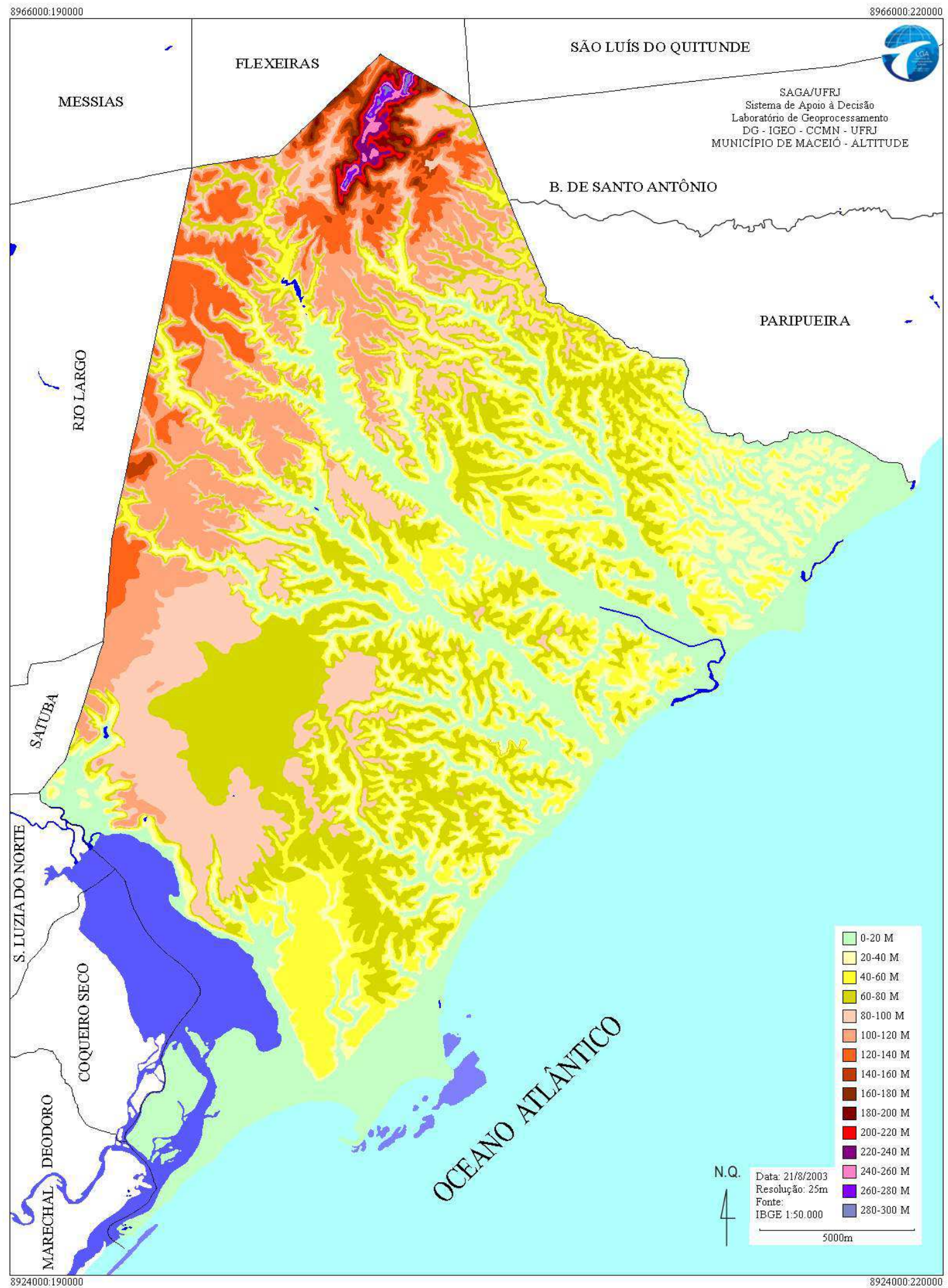

Figura 2 - Altitude município de Maceió. Fonte: LGA-IGDEMA-UFAL (2004).

Geo UERJ - Ano 15, no. 24, v. 1, $1^{\circ}$ semestre de 2013 p. 207-227

ISSN: 1415-7543E-ISSN: 1981-9021

http://www.e-publicacoes.uerj.br/index.php/geouerj 


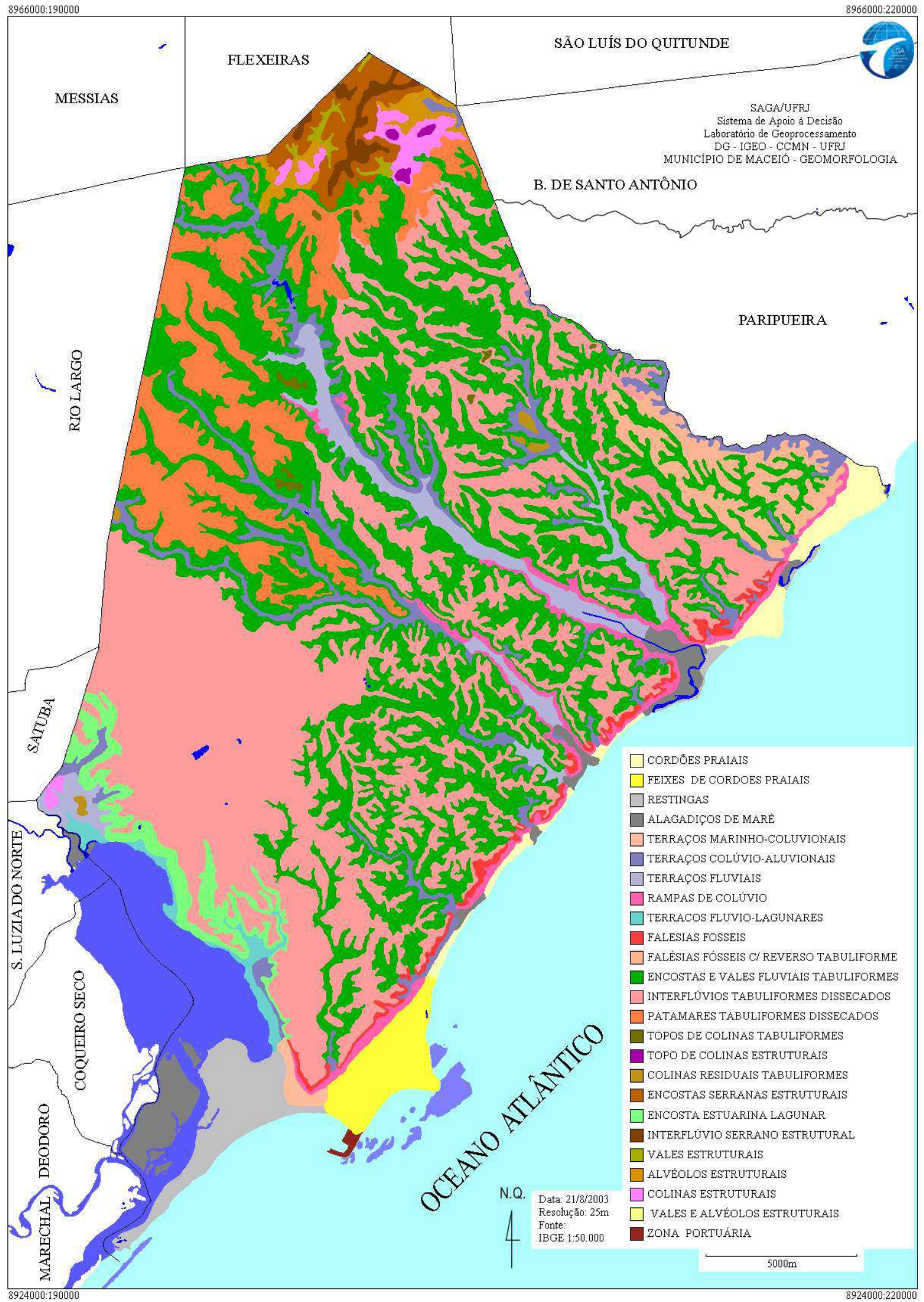

Figura 3 - Geomorfologia do município de Maceió. Fonte: LGA-IGDEMA-UFAL (2004).

Geo UERJ - Ano 15, no. 24, v. 1, $1^{\circ}$ semestre de 2013 p. 207-227

ISSN: 1415-7543E-ISSN: 1981-9021

http://www.e-publicacoes.uerj.br/index.php/geouerj 


\section{RESULTADOS E DISCUSSÃO}

Os resultados obtidos a partir da análise dos documentos cartográficos, da literatura existente, do reconhecimento de campo e pela análise das variáveis ambientais do município (LIMA et. al., 1995) permitiram identificar fenômenos como retirada de sedimentos por extração de areia das encostas, solo exposto pela ausência de cobertura vegetal e áreas de ocupadas em declividade comprometedoras a ocorrência de desastres naturais no município estudado. Silva (2011) cita como principais condicionantes dos movimentos de massa e processos correlatos os seguintes fatores: Clima, através da precipitação pluviométrica, que contribuirá para a concentração de processos de solifluxão e carreamento de material pelas encostas. A Vegetação, quando esta é retirada, o solo fica exposto, e propenso à erosão, e se tiver em áreas com acentuada declividade, o caso se agrava. As formas do relevo orientam os fluxos de materiais, nas encostas são percebidos processos erosivos nos topos e deposições na base, tornando áreas susceptíveis a movimento de massa e as planícies a enchentes. A Geologia, diante da natureza da rocha, que pode facilitar o processo erosivo ou retardar. A Ação Antrópica que causam impactos ambientais, que deixam o solo exposto, pela urbanização ou pelos cultivos diversos.

Do ponto de vista geomorfológico a área destaca-se por apresentar relevo ondulado, o qual contribui para ocorrência de movimentos de massas nas áreas de vulnerabilidade de relevo de encostas e falésias, diante da presença de declividade acentuada, principalmente no período chuvoso. Assim as categorias falésias, encostas e falésias fósseis receberam grau de possibilidade "Altíssimo", diferenciando-se nos topos do Tabuleiro e Patamares Tabuliformes (Tabela 1).

Geo UERJ - Ano 15, nº. 24, v. 1, $1^{\circ}$ semestre de 2013 p. 207-227

ISSN: 1415-7543E-ISSN: 1981-9021

http://www.e-publicacoes.uerj.br/index.php/geouerj 
Tabela 1 - Notas atribuídas para a Geomorfologia.

\begin{tabular}{|c|c|c|}
\hline GEOMOFOLOGIA & Peso $40 \%$ & Grau de nossibilidade \\
\hline Legendas & Notas & 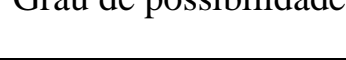 \\
\hline Cordões Praiais & 0 & Nula \\
\hline Feixes de Cordões Praiais & 0 & Nula \\
\hline Restingas & 0 & Nula \\
\hline Alagadiços de Maré & 0 & Nula \\
\hline Terraços Marinho-Coluvionais & 0 & Nula \\
\hline Terraços Colúvio-Aluvionais & 0 & Nula \\
\hline Terraços Fluviais & 0 & Nula \\
\hline Rampas de Colúvio & 0 & Nula \\
\hline Terraços Flúvio-Lagunares & 0 & Nula \\
\hline Falésias Fósseis & 9 & Altíssima \\
\hline Falésias Fósseis c/Reverso Tabuliforme & 10 & Altíssima \\
\hline Encostas e Vales Tabuliformes & 10 & Altíssima \\
\hline Interflúvios Tabuliformes Dissecados & 4 & Baixa \\
\hline Patamares Tabuliformes Dissecados & 7 & Alta \\
\hline Topos de Colinas Tabuliformes & 3 & Baixa \\
\hline Topo de Colinas Estruturais & 4 & Baixa \\
\hline Colinas Residuais Tabuliformes & 8 & Alta \\
\hline Encostas Serranas Estruturais & 9 & Altíssima \\
\hline Colinas Tabuliformes & 8 & Alta \\
\hline Encosta Estuarina Lagunar & 10 & Altíssima \\
\hline Interflúvio Serrano Estrutural & 4 & Baixa \\
\hline Vales Estruturais & 8 & Alta \\
\hline Alvéolos Estruturais & 6 & Média \\
\hline Colinas Estruturais & 8 & Alta \\
\hline Vales e Alvéolos Estruturais & 9 & Altíssima \\
\hline
\end{tabular}

Do ponto de vista litológico o que norteou a avaliação foi à importância adquirida pelos terrenos terciários do Grupo Barreiras (Tabela 2), constituídos por terrenos de sedimentos argilo-arenosos e argilosos com altíssima tendência a ocorrência de movimentos de massa, principalmente no período chuvoso. 
Tabela 2 - Notas atribuídas para a Litologia.

\begin{tabular}{|c|c|c|}
\hline LITOLOGIA & Peso $10 \%$ & Grou de noccibilidade \\
\hline Legenda & Notas & Urau ae possiontinate \\
\hline Formação Barreiras - Terciário & 9 & Altíssima \\
\hline Formação Penedo - Cretáceo & 7 & Alta \\
\hline Formação Muribeca Indiferencia - Cretáceo & 6 & Média \\
\hline Formação Muribeca Mem. Carmópolis -Cretáceo & 7 & Alta \\
\hline Batólito PE-AL - Pré-Cambriano & 8 & Alta \\
\hline Sedimentos de Praia e Aluvião - Quaternário & 3 & Baixa \\
\hline
\end{tabular}

As classes correspondentes a afloramentos de rochas do Cretáceo (Formação Penedo e Aracaré) e Pré-Cambriano (Cornubianito Jaramataia) apresentam-se em áreas de relevo com acentuada dissecação, ou seja, com encostas de acentuada declividade, diferenciando apenas para a Formação Penedo que aflora em declividades moderadas.

Este critério foi definidor para atribuir grau de possibilidade de alta e média participação dessas classes para ocorrência do fenômeno. É importante salientar que a nota 3 (para movimento de massa) atribuída para a classe sedimento de praia e aluvião, deve-se ao fato desta classe se apresentar agregada em duas (areias quartzosas e aluvião), limitando uma participação mais efetiva no processo de avaliação, mesmo assim não invalidaram a análise.

O parâmetro altitude reflete as diferenças hipsométricas de uma área que favorecem ou não a ocupação. No município de Maceió as variações altimétricas atingem de 0-220 m. A ocorrência de movimentos de massas está associada à influência de cotas altimétricas altas, o caso de movimentos de escorregamento e deslizamento (Tabela 3). Também, ocorrem movimentos de massas do tipo rastejo em áreas com altitudes elevadas e declividades menos acentuadas devido à ocupação humana, sendo indicativos para os desastres naturais.

Geo UERJ - Ano 15, no. 24, v. 1, $1^{\circ}$ semestre de 2013 p. 207-227

ISSN: 1415-7543E-ISSN: 1981-9021

http://www.e-publicacoes.uerj.br/index.php/geouerj 
Tabela 3 - Notas atribuídas para a de Altitude.

\begin{tabular}{ccc}
\hline ALTITUDE & Peso $15 \%$ & Grau de possibilidade \\
\hline Legenda (metros) & Notas & Nula \\
\hline $0-20$ & 0 & Baixíssima \\
$20-40$ & 1 & Baixa \\
$40-60$ & 2 & Média \\
$60-80$ & 5 & Baixa \\
$80-100$ & 4 & Baixa \\
$100-120$ & 3 & Média \\
$120-140$ & 5 & Média \\
$140-160$ & 6 & Alta \\
$160-180$ & 7 & Média \\
$180-200$ & 5 & Média \\
$200-220$ & 6 & Alta \\
$220-240$ & 7 & Alta \\
$240-260$ & 8 & Altíssima \\
$260-280$ & 9 & Altíssima \\
$280-300$ & 10 & \\
\hline
\end{tabular}

No que se refere à declividade, esta tem implicações na intensificação dos processos erosivos e a susceptibilidade a movimentos de massas. $\mathrm{Na}$ área a presença de declividades acima de $30^{\circ}$ são definidoras para ocorrência de movimentos de massa verificadas pela velocidade de escoamento, na qual há o aumento da taxa de percolação, que conduz ao escorregamento diante da inclinação da vertente (Tabela 4).

Tabela 4 - Notas atribuídas para a Declividade.

\begin{tabular}{ccc}
\hline DECLIVIDADE & Peso $30 \%$ & Grau de possibilidade \\
\cline { 1 - 2 } Legenda & Notas & Baixíssima
\end{tabular}

Geo UERJ - Ano 15, no. 24, v. 1, $1^{\circ}$ semestre de 2013 p. 207-227 
A topografia é um dos principais fatores naturais que determinam a velocidade dos processos erosivos e sua influência deve ser analisada pela ponderação de dois fatores: declividade e comprimento da encosta. Assim, a declividade tem tanto maior importância quanto maior for o trecho percorrido pela água que escoa, ou seja, quanto maior for o comprimento da encostas.

O macromodelado é um estudo geomorfológico que enfatiza a influência dos processos externos na construção das microformas do relevo (resultado da esculturação da superfície pelas águas superficiais e fatores climáticos), cuja ação sobre rochas de naturezas semelhantes, está condicionada direta ou indiretamente a fatores ambientais, que originam depósitos com características diferenciadas (acumulações, aplanamento e dissecação).

A modelado de acumulação, via de regra, situa-se na região de cotas altimétricas baixas, alagadiças e próximas a zonas de saturação. $\mathrm{O}$ de aplanamento corresponde a relevos planos, geralmente com pacote sedimentar espesso. O modelado de dissecação apresenta o predomínio de erosão vertical, cujos rios são mais violentos resultando em transportes rápidos de sedimentos e pouca deposição, intensificando os movimentos de massa, principalmente de deslizamento. Apresentam-se em áreas de relevo com acentuada dissecação, menos aplainadas. $\mathrm{Na}$ área, estão presentes em encostas com acentuada declividade (Tabela 5).

Tabela 5 - Notas atribuídas para as variáveis Macromodelados.

\begin{tabular}{cccc}
\hline MACROMODELADOS & Peso 5\% & \multirow{2}{*}{ Grau de possibilidade } \\
\hline Legenda & Notas & & Altíssima \\
\hline Modelado de Dissecação Homogênea & 9 & Média \\
Modelado de Acumulação e Deposição & 5 & Altíssima \\
Modelado de Dissecação Diferencial & 10 & Baixa \\
Modelado de Aplanamento & 3 & \\
\hline
\end{tabular}

Geo UERJ - Ano $15, n^{\circ} .24$, v. 1, $1^{\circ}$ semestre de 2013 p. 207-227 
Quando ocorre maior sedimentação e se inicia uma erosão horizontal (lateral), os sedimentos vão se acumulando pela perda de força dos rios, surgindo assim às superfícies de acumulação e aplanação, com predominância dos agentes externos, resultando em dissecação fluvial de rios com fortes meandros e erosão lateral. Estes correspondem a movimentos de massas causados por erosão lateral, cuja magnitude da dissecação pode provocar movimentos de massa.

\section{Avaliação do Potencial para movimentos de massas em Maceió - AL}

O potencial risco para movimentos de massas no município de Maceió diante da avaliação realizada foi classificado em 4 níveis (classes) de acordo com as notas alcançadas, que variaram de 0 a 10, representados no cartograma digital classificatório, com diferentes extensões em áreas distribuídas espacialmente.

Os potenciais para movimento de massas foram classificados em Baixíssimo, Baixo, Médio e Alto, com base nos resultados apresentados pelo cruzamento dos mapas (Figura 3). A Tabela 6 apresenta as classes definidas com respectiva planimetria e a percentagem sobre a área analisada.

Tabela 6 - Resultado da avaliação para potencial de ocorrência de movimento de massas, em Maceió - AL.

\begin{tabular}{ccc}
\hline Legenda & Há & $\%$ \\
\hline Baixíssimo & 8038.6250 & 16.08 \\
Baixo & 15379.1875 & 30.76 \\
Médio & 18541.9375 & 37.09 \\
Alto & 8021.6875 & 16.04 \\
\hline
\end{tabular}

$\mathrm{O}$ alto potencial risco abrange 8021.6875 ha, atingindo $16,04 \%$ do município estudado. Encontra-se dispersa no entorno da área correspondente a classe de médio potencial. A ocorrência da classe foi localizada em duas áreas: Área 1 (vales fluviais e encostas laterais tanto na porção norte - noroeste e sul do município) e Área 2 (dispersa ao longo do das encostas dos vales e borda dos tabuleiros costeiros).

Este baixo percentual de área de ocorrência de alto potencial para movimento de massa é decorrente de sua localização nas encostas e borda dos tabuleiros, no entorno 
DOI: $10.12957 /$ geouerj.2013.5351

do sítio urbano de Maceió, que diante de trabalho de campo identificou-se ser áreas de uso residencial de baixa renda, de grande susceptibilidade a desastres.

Geo UERJ - Ano 15, nº. 24, v. 1, $1^{\circ}$ semestre de 2013 p. 207-227 ISSN: 1415-7543E-ISSN: 1981-9021

http://www.e-publicacoes.uerj.br/index.php/geouerj 


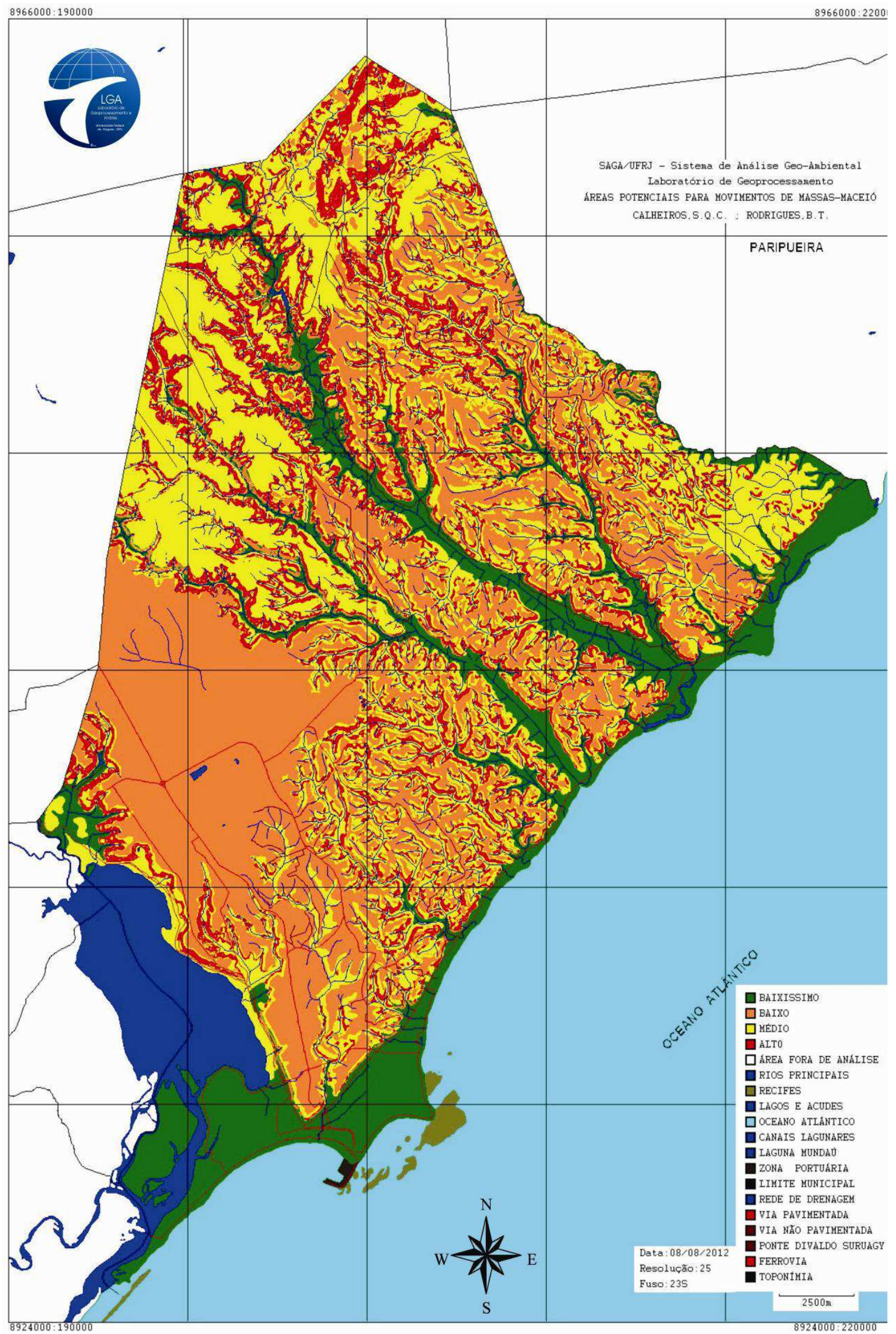

Geo UERJ - Ano 15, no. 24, v. 1, $1^{\circ}$ semestre de 2013 p. 207-227

ISSN: 1415-7543E-ISSN: 1981-9021

http://www.e-publicacoes.uerj.br/index.php/geouerj 
Figura 3 - Mapa do potencial de risco para a ocorrência de movimento de massas.

O Médio Potencial da classe analisada abrange uma área de 18541.9375 ha, atingindo 37,09\% do território estudado. Este está concentrado no entorno da área correspondente a classe de baixo potencial, em áreas de bordas, encostas e modelados dissecados com ocorrência em duas áreas: Área 1 (Dominante a oeste e norte do município, com ocorrência nos patamares tabuliformes dissecados) e Área 2 (Borda do tabuleiro costeiro sul do município, penetrando para o centro da cidade de Maceió). O que é preocupante é sua ocorrência sobre a cidade de Maceió, área urbana edificada, de alta vulnerabilidade a desastres naturais, principalmente nas áreas de patamares tabuliformes e bordas dos tabuleiros costeiros.

Em relação ao Baixo Potencial, a distribuição geográfica desta classe abrange uma área de a 15379.1875 ha, equivalente a 30,76\% do total da área em estudo. Esta se encontra mais concentrada no entorno da área correspondente a classe de médio potencial. É importante salientar que essas áreas não perderam totalmente sua potencialidade, cuja vulnerabilidade está diante da ocupação nos topos dos tabuleiros dissecados com ocupação humana. A ocorrência da classe foi localizada somente na Área 1 Dominante sobre as superfícies tubuliformes dissecadas aos sul do município correspondendo a área habitada da cidade de Maceió). O Baixíssimo Potencial tem distribuição geográfica concentrada no entorno da área correspondente a classe de baixo potencial, correspondente a 8038.625 ha, representando $16,08 \%$ do total da área em estudo. Verifica-se que esta, perde totalmente sua potencialidade, se caracterizando com área contribuinte para desastres naturais, atrelados a processos vinculados a enchentes. A ocorrência da classe foi localizada em duas áreas: Área 1 (Dominante a leste na área dos cordões arenosos, penetrando sobre a restinga) e Área 2 (Várzeas e planície fluviais e terraços fluviais e marinhos).

Cabe ainda mencionar que nas áreas de uso tradicionalmente agrícola demonstraram alta ocorrência de situações territoriais conflitantes para ocorrências de desastre naturais.

Geo UERJ - Ano 15, nº. 24, v. 1, $1^{\circ}$ semestre de 2013 p. 207-227

ISSN: 1415-7543E-ISSN: 1981-9021

http://www.e-publicacoes.uerj.br/index.php/geouerj 


\section{CONCLUSÕES}

A avaliação potencial ambiental para movimento de massas é identificado como um dos definidores de ocorrência de desastres naturais.

A utilização e análise de documentos cartográficos, da literatura existente, de reconhecimento de campo e pela análise das variáveis ambientais do município estruturadas em bancos de dados geográficos existentes permitem identificar situações definidoras de ocorrência de desastres naturais, entre eles de movimento de ma

A avaliação das áreas de movimento de massas conduziram à localização e a identificação de áreas com alto, médio, baixo e baixíssimo potenciais para ocorrência da situação analisada, prováveis para desastres naturais.

Pela análise verifica-se que áreas com alto potencial de movimento de massa são áreas povoadas das áreas habitadas no município de Maceió conjugadas as condições das edificações.

As áreas de uso tradicionalmente agrícola demonstraram alta ocorrência de situações conflitantes para ocorrências de desastre naturais.

A tecnologia de Sistemas Geográficos de Informação apresentou uma visão integradora, sendo um poderoso instrumento de análise ambiental visando o apoio a decisão.

\section{Referencias}

ASSIS, J. S.. Biogeografia e conservação da biodiversidade:projeções para Alagoas. Maceió: Catavento, 2000. 199 p.

BISPO, P. C.; ALMEIDA C. M.; VALERIANO, M.; MEDEIROS, J. S.; CREPANI, E. Análise da susceptibilidade aos movimentos de massa em São Sebastião (SP) com uso de métodos de inferência espacial. São Paulo: UNESP/ Geociências, 2011. 100 p.

CALHEIROS, S. Turismo versus agricultura no litoral meridional de Alagoas. Rio de Janeiro: UFRJ. 2000. v.1 e 2.Tese (Doutorado em Geografia - Centro de Ciência Exatas e da Natureza) Universidade Federal do Rio de Janeiro, Rio de Janeiro.

CARVALHO FILHO, L. M.S, de; ABDOO, E. (1999). Pré-processamento. In: LAGEOP-CEGEOP (MULTIMÍDIA).

CHORLEY, R. Geomorphology. London: Methuen \& CO. Ltd., 1984, 160 p. 
CHRISTOFOLETTI, A. Geomorfologia. São Paulo: Edgard Blucher Ltda/EDUSP. 1974. $130 \mathrm{p}$.

DNPM. Mapa geológico do Estado de Alagoas: texto explicativo. Recife: DNPM. (Série mapas e cartas sínteses 2, seção geológica, 2)., 1986, 90p.

FERNANDES, N. F.; AMARAL, C. P. Movimentos de massa: uma abordagem geológico-geomorfológica. In GUERRA, A. J. T.; CUNHA, S. B. (org.) Geomorfologia e meio ambiente. Rio de Janeiro: Bertrand, p.123-194. 1996.

GÓES, M. H. Diagnóstico ambiental por geoprocessamento do município de Itaguaí (RJ). Rio Claro: UNESP. 1994. v. 1. Tese (Doutorado em Ciências) - Centro de Ciências Naturais, Universidade Estadual de São Paulo, Rio Claro, 1994.

GUERRA, J. A. T. Encostas Urbanas. In: GUERRA, J. A. T. Geomorfologia urbana. Rio de Janeiro: Bertrand Brasil, 2011, 280 p.

INSTITUTO DE PESQUISAS TECNOLÓGICAS DO ESTADO DE SÃO PAULO S.A. (IPT). Controle de erosão. São Paulo: DAEE-IPT, 1989, 174 p.

TOMINAGA, L. K. SANTORO, J.; AMARAL, R. do. Desastres naturais: conhecer para prevenir. São Paulo: Instituto Geológico, 2009. 50 p.

LIMA, L. C. A.; XAVIER DA SILVA, J.; GÓES, M. H. DE B.; COSTA, J. de A.; MENDES JR., S. A. G.; RAMOS, V. A.; CALHEIROS, S. Q. C.; ABDOL, O.; BERGAMO, R. B. A.; VELOZ, J. Análise ambiental de municípios por geoprocessamento: Maceió e sua área de influência. Revista de Geociências. Departamento de Geologia e Topografia - GET/CCEN/UFAL. Maceió, n. 6, p. 89-97, 1994.

PONTE, F. C. Estudo mofo-estrutural da Bacia Sergipe-Alagoas. Boletim Técnico da Petrobrás, n.12, Rio de Janeiro, p.439-474. 1969.

RADAM BRASIL. Folhas SC24/25 Aracaju/Recife: geologia, geomorfologia, pedologia, vegetação e uso potencial da terra. Rio de Janeiro: IBGE,1983, 856 p. (Levantamento de Recursos Naturais, 30).

SOUZA, C. R. G. Risco a inundações, enchentes e alagamentos em regiões costeiras. In: SIMPÓSIO BRASILEIRO DE DESASRTES NATURAIS, 1, 2004, Florianópolis. Anais... Florianópolis: GEDN/UFSC, 2004. p.231-247. (CD-ROM)

SOUZA, J. L. de; AQUINO, L. C. L. de. Frequência quinzenal de precipitação pluvial em Alagoas. X CONGRESSO BRASILEIRO DE AGROMETEOROLOGIA. 1997. Piracicaba. Anais... Piracicaba: SBMET 1997, p.40-60. 
SOUZA, J. L. Características pluviométricas representativas do tabuleiro costeiro de Alagoas, período 1972-1996. VII CONGRESSO BRASILEIRO DE METEOROLOGIA, 1998, Brasília, Anais... Brasília, 1998, p.47-61.

XAVIER-DA-SILVA, J; CARVALHO-FILHO, L. M. Sistemas de Informação Geográfica: uma proposta metodológica. IV CONFERÊNCIA LATINO-AMERICANA SOBRE SISTEMAS DE INFORMAÇÃO GEOGRÁFICA, 1993, São Paulo. Anais... São Paulo,1993, p. 609-628.

Artigo recebido para publicação em março de 2013.

Artigo aceito para publicação em junho de 2013. 